\title{
EN TORNO A LA FUNDAMENTACIÓN DE LA DIGNIDAD PERSONAL
}

\author{
Blanca CAstilla de CoRTÁzAR \\ Académica de Número de la \\ Real Academia de Doctores de España \\ blancascor@gmail.com
}

\begin{abstract}
RESUMEN
Las trágicas experiencias de las guerras mundiales llevaron a la Declaración Universal de los Derechos Humanos promovida por la ONU en 1948. A partir de entonces gran parte de las Constituciones de nueva creación reconocen la inviolabilidad de la dignidad humana. Sin embargo, los redactores de la declaración pusieron empeño en omitir las razones teóricas en las que se fundan dichos derechos, por el temor a que diferencias teóricas aplazaran o bicieran inviable dicho reconocimiento. La fragmentación en la que se halla la antropología filosófica desde bace varios siglos está reclamando un principio unificador de los saberes en torno al ser bumano. En este contexto la dignidad bumana como experiencia universal se presenta como principio unificador. Seis décadas después sigue pendiente la elaboración de una sólida, y también universalmente aceptable, fundamentación de la dignidad bumana y sus derechos fundamentales, cuestión complicada que parece requerir un nuevo avance en la ontología y en la antropología filosófica.
\end{abstract}

Palabras clave: persona, dignidad, derechos humanos, antropología filosófica.

\section{ABSTRACT}

World wars I and II lead to the Universal Declaration of Human Rights, promoted by the UN in 1948. From then on most of the new born Constitutions bave been claiming dignity immunity for the buman being. However, those who penned the declaration made an effort to avoid the theoretical reason such rights are based upon, fearing that theoretical divergences postponed or turned unfeasible such recognition. The fragmentation philosophical anthropology has been living for centuries claims a principle that unifies knowledge around the buman being. It is within such context that the universal experience which is buman dignity appears to be a unifying principle. Six decades later, we are still lacking a ground and globally acceptable base for buman dignity and its fundamental rights, a complex issue that appears to require a new step in the fields of philosophical anthropology and ontology.

Keywords: People, dignity, human rights, philosophical anthropology.

\section{ZUSAMMENFASSUNG}

Die tragischen Erfabrungen der Weltkriege führten zur Erklärung der Allgemeinen Menschenrechte, wie sie 1948 von der UNO erarbeitet wurden. Ab diesem Zeit- 
punkt haben viele der neuen Staatsverfassungen die Unverletzlichkeit der Menschenwürde anerkannt. Jedoch vermieden es die Verfasser der Menschenrechtserklärung, theoretische Begründungen zu benennen, auf denen die Menschenrechte fußen, damit nicht theoretische Differenzen die Anerkennung der Menschenrechte binausschieben oder gar verunmöglichen konnten. Die Zersplitterung, in der sich die philosophische Anthropologie seit mehreren Jabrbunderten befindet, fordert, bezogen auf das menschliche Wesen, ein verbindendes Kenntnisprinzip. In diesem Kontext erweist sich die Menschenwürde als einheitsstiftendes Prinzip. Sechs Jahrzehnte danach steht weiterhin eine solide und allgemein akzeptierte Grundlegung der Menschenwürde und seiner Menschenrechte aus. Es scheint als würde diese komplizierte Frage einen neuen Fortschritt im Bereich der Ontologie und der philosphischen Anthropologie erforderlich machen.

Schlüsselwörter: Person, Würde, Menschenrechte, philosphische Anthropologie.

SUMARIO: I. INTRODUCCIÓN.-II. PROBLEMATICIDAD Y FRAGMENTACIÓN DE LA ANTROPOLOGÍA.-III. LA DIGINIDAD COMO UN PRINCIPIO UNIFICADOR.-IV. CONVENIENCIA DE FUNDAMENTAR LA DIGNIDAD.-V. REFLEXIÓN EN TORNO A LA DIGNIDAD HUMANA.-VI. LA DIGNIDAD COMO VALOR UNIVERSAL: SIGNIFICADO Y ALCANCE.

\section{INTRODUCCIÓN}

La modernidad sitúa al ser humano en el centro de su reflexión, y por obra de Kant, y más tarde de Feuerbach, la antropología pasa de ser una filosofía segunda derivada de la metafísica a adquirir autonomía y carácter propio versando sobre temas específicos del espíritu, siendo la libertad su piedra angular.

Son conocidos, sin embargo, los tortuosos caminos de la andadura antropológica y la exaltación de un individuo solitario que se relaciona únicamente con sus fuerzas con el Estado-leviatán hobberiano - al que previamente ha donado pasiones y derechos-, con la consiguiente disolución de la sociedad. La aparición de la sociología intenta rescatar los datos sociales, frecuentemente reconstruidos políticamente sobre colectivismos sin alma y donde el ser humano termina perdiendo el espíritu en materialismos autoclausurados. Finalmente, tras haber sido anunciada por Nietzsche la muerte de Dios se desencadenó la muerte del hombre. Y no sólo teóricamente, el fruto amargo de las ideologías han sido los millones de muertos que aún hoy vienen provocando los desastres bélicos en todas las partes de mundo.

«En la actual sociedad post-secular [...], sobre las cenizas del viejo sujeto empírico surge un nuevo sujeto "tecnocrático" que amenaza con dejar al 
primero reducido a objeto, como una simple prótesis, una mera función del nuevo e inquietante sujeto colectivo. En esta perspectiva Jongen ha llegado a definir al hombre, con un énfasis propio de Fausto, "como su propio experimento" $\gg^{1}$. Dicho con otras palabras, en el momento actual asistimos a otro modo de abolición del hombre ${ }^{2}$, a una falsificación que se presenta como un nuevo salto evolutivo de la raza humana donde, gracias a la tecnología, todo será a la carta, incluido el sexo y el género 3 .

\section{PROBLEMATICIDAD Y FRAGMENTACIÓN DE LA ANTROPOLOGÍA}

Todo ello da cuenta de la profunda confusión que se cierne, en el momento presente, en torno a la cuestión antropológica, que adolece de una profunda problematicidad ya descrita, a comienzos del siglo xx, por Max Scheler: «Poseemos una antropología científica, otra filosófica y otra teológica que no se preocupan una de la otra. Pero no poseemos una idea unitaria del hombre. Por otra parte, la multitud siempre creciente de ciencias especiales que se ocupan del hombre ocultan la esencia de éste mucho más de lo que la iluminan, por valiosas que sean. Si se considera, además, que los tres citados círculos de ideas tradicionales están hoy frecuentemente quebrantados, y de un modo muy especial la solución darwiniana al problema del origen del hombre, cabe decir que en ninguna época de la historia ha resultado el hombre tan problemático para sí mismo como en la actualidad» ${ }^{4}$.

La actual fragmentación antropológica procede de causas variadas y complejas, entre ellas, la diversidad de ciencias que la abordan y la ausencia de un verdadero trabajo interdisciplinar; dispersión que viene motivada de forma más radical por la crisis e incluso negación de la naturaleza humana - fundamento en el que se ha apoyado su universalidad- y, sobre todo, por el débil y escaso pensamiento acerca del ser y de la persona, un ámbito de la realidad humana más profundo que el de la naturale-

1 A. SCOLA, «La gratuidad, esa revolución económica», Huellas, núm. 13, n. 9 (2009), pp. 48-51. Cfr. también del mismo autor Buone ragioni per la vita in comune. Religione, politica, economia, Milano, Mondadori, 2010 (trad. esp. en Madrid, Encuentro, 2012, pp. 73-88).

2 Crisis antropológica diagnosticada hasta en el mismo título de algunos ensayos. Cfr.

C. S. LEWIs, La abolición del hombre, 6. ${ }^{a}$ ed., Madrid, Encuentro, 2012.

3 Según las propuestas de las teorías Cyborg y Queer.

${ }^{4}$ M. SCHeler, El puesto del hombre en el cosmos, 6. ${ }^{a}$ ed., Losada, Buenos Aires 1967, p. 24.

Foro, Nueva época, vol. 18, núm. 1 (2015): 61-80 
za. Por otra parte, las críticas de la posmodernidad y el difundido afán de deconstrucción de un pensamiento autosuficiente amenazan con el hundimiento de toda una civilización.

La situación presente reclama repensar lo que sigue estando vivo de la tradición —así como cuáles son sus límites o errores para poder superarlos- y proseguir la siempre abierta tarea antropológica. Los esfuerzos teóricos realizados a lo largo del siglo xx por un gran número de pensadores han ido trazando una nueva línea de pensamiento - distinta del nihilismo reinante en las teorías más ampliamente divulgadas-, orientada hacia una antropología realista, unitaria e interdisciplinar en busca de su fundamentación.

Adentrados en el tercer milenio el debate antropológico no consigue ofrecer una visión unitaria. Se enuncian y elaboran propuestas, pero falta un planteamiento lo suficientemente profundo que contribuya al logro unitario. Hay buenas señales y aspiraciones que permiten auspiciar la pronta realización de dicho proyecto. Pero no basta con aspirar — se aspira a lo que no se tiene- - sino que es preciso que dicho anhelo se convierta en real y, sobre todo, sea efectivo y esté presente en la experiencia personal y social. Que penetre y deje sentir sus efectos en el cuerpo social todo, iluminando los problemas antropológicos más acuciantes para el hombre actual, como pueden ser la fundamentación de la dignidad humana, la articulación de la libertad con la propia dignidad, una explicación de la condición sexuada y una articulación entre sexo-género que se armonice con el resto de dimensiones humanas. En el presente trabajo nos detendremos únicamente en la necesidad de fundar la dignidad personal.

\section{LA DIGNIDAD COMO UN PRINCIPIO UNIFICADOR}

En orden a conseguir una visión unitaria de la antropología se precisa ante todo un principio unificador. El método para encontrarlo no puede ser otro que volver a la experiencia humana elemental, siempre nueva, que permite acceder a propuestas realistas ${ }^{5}$. La experiencia es el punto de partida del conocimiento. Se puede tener experiencia de la belleza de un atardecer, del miedo ante un peligro, de cómo resolver un tipo de problemas o de haberse enamorado. Los descubrimientos más valiosos que dan senti-

${ }^{5}$ Cfr. A. Scola, La experiencia bumana elemental. La veta profunda del magisterio de Juan Pablo II, Madrid, Encuentro, 2005. 
do a la vida han tenido lugar atravesando la vivencia del amor y del dolor. Con frecuencia, en los momentos de crisis - si no se cede a la desesperación- es cuando se plantean las cosas más a fondo y se pueden conseguir sólidas convicciones. Y las crisis pueden ser personales o de toda una civilización o momento histórico donde la crisis es generalizada.

Pues bien, aquí vamos a hacer referencia a una convicción que alcanzó, al menos por un tiempo, la humanidad casi al completo tras la Segunda Guerra Mundial a través de la experiencia del dolor. Habían sido seis largos años de mucho sufrimiento, de privaciones, ciudades destruidas, millones de muertes y de personas perseguidas por su raza o por sus ideas. Se había vivido sin la libertad de poder expresar las propias ideas, ocultándolas para poder sobrevivir, se quemaban públicamente los libros para que la gente no tuviera en la mente más que las consignas de los partidos. Y miles de personas pasaron penalidades sin fin en los campos de concentración.

Quienes sobrevivieron a ellos fue gracias a convicciones que marcaron su intimidad con una fuerza casi indeleble. Relata Hannah Arendt ${ }^{6}$ que allí se fomentaba deliberadamente el sin sentido: se humillaba a los prisioneros de todos los modos posibles para que se convencieran de que eran piltrafas humanas, seres sin valor no dignos para estar en la existencia. En esas circunstancias de trabajos extenuantes — donde no había para comer ni para beber y donde eran vejados, insultados, apaleados- no era difícil odiar. Y ese odio les consumía hasta la muerte, si antes no habían sido gaseados. Víctor Frankl, que tenía cierta experiencia, por su profesión de psiquiatra, de bucear en la intimidad humana, advirtió que el odio provocaba la muerte. Quizá el detonante fuera el «instinto» de supervivencia, pero lo cierto es que la vivencia experiencial del total despojo - trabajo, familia, ropa, comida, salud...- hizo visible y viva su libertad interior. Poseía algo que era tan suyo que no pertenecía a nadie más y que nadie le podía arrebatar: su intimidad. Y comenzó a reavivar y fomentar en su mundo interior los gratos recuerdos, los momentos felices, el amor de su mujer, el ejercicio de su trabajo vocacional. Mientras le molían a trabajos físicos forzados, a hambre y sed, pensaba en cómo podría ayudar y trasmitir a otros lo que estaba viviendo, de modo que aquella vida tan absurda, sufriente, humillante y alienante comenzó a tener sentido ${ }^{7}$.

Esta experiencia no fue algo aislado; fueron muchas, millones, las personas que padecieron los horrores de la guerra quedándose sin nada: sin

\footnotetext{
${ }^{6}$ Cuestión narrada en la reciente película que lleva su nombre (2013).

7 V. Frankl, El hombre en busca de sentido, 2. ${ }^{a}$ ed., Barcelona, Herder, 2001.
} 
seres queridos, sin bienes materiales, sin salud, mutilados física y psíquicamente. Tras tantos horrores se produjo un sentimiento común de que había cosas que eran inviolables, intocables, que si queríamos que el mundo marchara mejor debíamos coincidir en algo irrenunciable: el respeto al otro como base de la convivencia universal interplanetaria. De un modo colectivo se fue consciente de la dignidad humana y se reconoce por parte de todos los pueblos —incluida China, que carecía de esos vocablos- la universalidad de los derechos humanos.

Fue así como en el siglo Xx, a través de una experiencia vital, sangrienta y homicida, se atisbó un principio verdaderamente universal y unificador para la antropología: la dignidad humana, quizá por la nostalgia de su ausencia — «se canta lo que se ha perdido» dice certeramente Antonio Machado - , al haber sido lacerada entonces con más crudeza que en ningún otro periodo histórico. Se trató de una experiencia vital, no de un mero proceso teórico, a través de la que se advirtió con crudeza el malestar de la cultura - como reza el título de la obra de Freud- en el seno de las ideologías individualistas o colectivistas en las que las personas resultan gravemente lesionadas y en las que la dignidad personal y los derechos humanos que le son debidos e inalienables emergieron con fuerza, haciendo surgir un «pathos» nuevo que permitió e hizo posible avanzar notoriamente el acervo sapiencial de la humanidad: la inviolabilidad de la dignidad humana y la universalidad los derechos humanos, que cobran efectividad plena en la Declaración Universal de los Derechos Humanos aprobada por las Naciones Unidas en París el día 20 de diciembre de 1948, sobre las ruinas aún humeantes de los recientes bombardeos.

\section{CONVENIENCIA DE FUNDAMENTAR LA DIGNIDAD}

En cada ser humano, la conciencia de la dignidad comienza al experimentar que nadie le puede arrebatar la libertad interior de la que es poseedor, valor absoluto que cada uno tiene por el hecho de serlo. Esta conciencia individual, como venimos diciendo, a mediados del siglo pasado fue experimentada al mismo tiempo por muchas personas a la vez, lo que motivó que desde principios de 1947 la Comisión de Derechos del Hombre de las Naciones Unidas empezara a preparar la declaración universal de la misma. Para investigar de los problemas teóricos que podría suscitar, la Comisión decidió solicitar la colaboración de las mentes más prestigiosas del momento a través de un amplio cuestionario remitido, entre 
otros, al filósofo, historiador y político italiano Benedecto Croce; al pensador y líder hindú Mahatma Gandhi; al novelista inglés Aldous Huxley; al también politólogo inglés Harold Laski; al diplomático e historiador español Salvador de Madariaga, y a los filósofos franceses Pierre Teilhard de Chardin y Jacques Maritain. Como relata este último, en una de las reuniones conjuntas uno de los asistentes manifestó su extrañeza al comprobar que personas que tenían pensamientos no sólo distintos, sino enfrentados, estuvieran de acuerdo en redactar una misma lista de derechos. Ellos contestaron: «Sí, estamos de acuerdo en esos derechos a condición de que no se nos pregunte por qué», manifestando que eran los opuestos porqués los que podían enfrentarles ${ }^{8}$.

La respuesta evidencia las dificultades especulativas que entrañan la fundamentación y justificación de los derechos humanos, especialmente para los juristas, por lo que en la redacción de la Declaración se puso un exquisito cuidado en eludir todo aquello que se refiriera a las razones que avalan su evidencia jurídica. A pesar de todo, con la Declaración Universal de los Derechos (1948) se había logrado al fin que de forma expresa la dignidad humana y los derechos que le son inherentes quedaran reconocidos, de forma perdurable, en un texto legal supranacional que, como postulado básico o principio/valor fundamental, siguen asumiendo y suscribiendo los actuales Estados de Derecho constitucionales.

Palacios señala que la falta de fundamentación de dicho texto plantea diversos problemas. El primero de carácter práctico, porque aunque aquellos expertos dijeran no tener las mismas razones, no parecían carecer de ellas, lo cual explica su común adhesión. Ahora bien, si proponían una relación de derechos a la aceptación mundial ¿qué esperanza podían tener de conseguirla si eludían invocar toda razón que la aconsejara? Pero el principal inconveniente, sigue argumentando Palacios, es la condición amenazada y provisional que tienen las opiniones verdaderas, conseguidas de un modo espontáneo o precientífico si no están fundamentadas ${ }^{9}$, como bien expresara Platón en boca de Sócrates cuando afirma: «Las opiniones verdaderas, en tanto que duran, son una cosa bella y todo lo hacen bueno; pero no gustan de permanecer mucho tiempo, sino que se escapan del alma del hombre y así no valen gran cosa, hasta que se las encadena con la consideración del fundamento» ${ }^{10}$.

${ }^{8}$ Cfr. J. MARITAIN et al., «Introduction», en Autor de la nouvelle Déclaration Universelle des Droits de l'Homme, Paris, Sagittaire, 1949, pp. 11-18.

9 Cfr. J. M. Palacios, La condición de lo bumano, Madrid, Encuentro, 2013, p. 36.

${ }^{10}$ Platón, Menón, 97e-98a. 
Sin una adecuada fundamentación, la dignidad personal y de los derechos humanos, aunque puedan ser reconocidos incluso universalmente, están expuestos a decaer al arbitrio de opiniones humanas mudables e interpretaciones meramente positivistas. De hecho, en las últimas décadas —además de los derechos fundamentales sobre la vida, la educación, la libertad para contraer matrimonio, la libertad religiosa o de expresión - asistimos a una proliferación creciente de derechos «de segunda, de tercera o de cuarta generación», llegando hasta el extremo de querer convertir los simples deseos en derechos. Y pueden presentarse contradicciones tales como que, en virtud de algunos de esos derechos añadidos, se conculquen derechos fundamentales de otros, como el caso del derecho a la vida del nasciturus con el recientemente invocado derecho al aborto.

Es un hecho también que tras décadas después de su reconocimiento jurídico en el Derecho positivo y de que la dignidad humana, unida a los derechos humanos, sea temática omnipresente en la reflexión antropológico-jurídica del siglo xx, sigue vigente su desvinculación con una fundamentación, lo que, desde el punto de vista teórico, no deja de ser una falta de rigor. «Nuestra cultura está dividida no sólo en temas más prácticos como son el aborto o la eutanasia, sino en otros más teóricos como son la admisión de los momentos ontológicos en los razonamientos jurídicos o la afirmación de la condición personal del ser humano. Hay, sin embargo, una estrecha correlación entre teoría y praxis» ${ }^{11}$. Esta preocupación es frecuente entre los juristas ${ }^{12}$, en particular entre aquellos que advierten la incoherencia que existe en la disociación entre dos ámbitos que se alimentan uno al otro. En consecuencia, se está manteniendo una praxis - que anteriormente tuvo una implícita fundamentación en la dignidad - silenciando u omitiendo las razones que la fundan, lo que tarde o temprano hace peligrar la continuidad de dicha praxis.

${ }^{11}$ Cfr. Fr. Carpintero, «¿Pueden las teorías sobre la justicia sustituir a la doctrina de la ley natural?», Persona y Derecho, núm. 66-67 (2012), pp. 315-316. En el marco de este segundo grupo han aparecido diversas teorías sobre la justicia - pensemos en HABERMAS o RAWLS- que tienen en común su igual negación (o no mención) de la cualidad personal del hombre y la sustitución de la personalidad de los hombres por construcciones racionales que normalmente están basadas en la igualdad de los sujetos. Resultaría así que los sujetos deben sus derechos a teorías o razonamientos que les atribuyen esos derechos en virtud de la exigencia de la igualdad de los individuos; unos razonamientos que tratan a los seres humanos «como si» fueran personas, pero sin afirmar que lo sean.

12 Se escriben voluminosos estudios que hablan de este interés. Cfr. F. Fernández SegaDO (coord.), Dignidad de la persona, derechos fundamentales, justicia constitucional, Madrid, Dykinson, 2008. 
Por esta razón, la dispersión del pensamiento contemporáneo reclama una sólida fundamentación racional y filosófica de la dignidad en algo previo a la acción. Ahora bien, esta heurística requiere clarificar en qué puede consistir ese algo previo. Lo previo ¿sería la naturaleza humana, el derecho natural? La pregunta radica es saber si los derechos humanos remiten en último término a la naturaleza humana o a una instancia aún más profunda. Asunto nada sencillo que lleva a Palacios a reconocer que, aunque no faltan quienes la conocen de un modo intuitivo, de momento no hay una explicación teórica convincente a tan grave y necesaria cuestión. Sin embargo, «semejante respuesta —afirma—, muy lejos de abonar cualquier fácil contento o abandono en la investigación, manifiesta ante todo la necesidad de proseguir y perfeccionar el discurso filosófico acerca de él, cuyas inveteradas dificultades no justifican nunca reducirse al silencio. Pues, si no todo hombre, al menos el filósofo tiene siempre que decirse a sí mismo y explicar igualmente al que se lo pregunta qué sabe, qué no sabe y qué quiere saber» ${ }^{13}$.

En orden a «proseguir» en la búsqueda de la fundamentación a la que nos invita Palacios dedicamos las siguientes páginas a recoger los presupuestos histórico-espirituales de la misma siguiendo al constitucionalista alemán Christian Starck ${ }^{14}$. El autor reconoce la variedad de comprensiones de la dignidad que se han ido elaborando: la concepción cristiana, la humanista-ilustrada, la marxista, la teórico-sistemática o la behaviorista, pero lo que no le resulta admisible es que esa pluralidad de significados devenga en una resignación escéptica que justifique la pasividad respecto a seguir intentando una fundamentación más universal de la misma. En su opinión hay un hecho concreto al que todos han de atender: la posición del hombre frente al Estado reclama la necesidad de garantizar la dignidad humana. Ese compromiso permite reconocer caminos erróneos, levantarse de abismos profundos y buscar nuevos caminos, para lo cual el análisis de Starck aconseja, en primer lugar, volver al origen histórico y a las razones por las que la dignidad humana comenzó a tener vigencia social dentro de la cultura europea.

Ese punto de partida es el hecho irrefutable de que la valoración del ser humano en la cultura occidental es mucho más elevada que en otras cul-

13 Cfr. J. M. Palacios, La condición de lo bumano, op. cit., p. 61.

${ }^{14}$ Cfr. Ch. Starck, «La dignidad del hombre como garantía constitucional, en especial en el Derecho alemán», en Fr. FERnÁndez SEgADO (coord.), Dignidad de la persona, derechos fundamentales, justicia constitucional, Madrid, Dykinson, 2008, pp. 241-247, donde el autor recoge los fundamentos históricos-espirituales. 
turas y en la génesis de tan alta apreciación hay que reconocer la influencia del cristianismo. En efecto, las razones que han hecho posible la conciencia de la dignidad están presentes en la imagen cristiana del hombre, y aunque no se sea cristiano no puede pasar inadvertida esa herencia espiritual en el estudio de la actualidad. Dicho con otras palabras, si en la cultura europea - cuando el ser humano ha sido denigrado - se ha podido sentir una nostalgia tan profunda de la dignidad perdida es porque durante siglos muchas generaciones han tenido unas convicciones acerca del ser humano que proceden del cristianismo.

A continuación Starck señala las que considera nucleares. En primer lugar, tanto en el Antiguo como en el Nuevo Testamento el hombre aparece creado a imagen y semejanza de Dios (Gén. 1,27; Ef. 4,24) y teniendo una relación personal con Dios, como queda de manifiesto en la inmortalidad y en la responsabilidad ante Él. Eso conlleva que la libertad individual sea el concepto central de la teología cristiana, condición para la culpa y la expiación. Tal fundamentación se corresponde con la comprensión de la realidad humana como inacabada y con un espíritu abierto ${ }^{15}$, donde se encuentra el fundamento para la libertad, la igualdad y la fraternidad, ya que todos los hombres son iguales a los ojos de Dios.

Desde esta visión, por tanto, la dignidad no significa simplemente la autodeterminación, sino la autodeterminación como el fundamento del valor propio de todo hombre y de todos los hombres. Esa concepción del hombre es la que ha permitido a muchas generaciones comprender la dignidad personal y manifestar la necesidad de asegurarla jurídicamente, y, por tanto, es en ella donde hay que buscar las bases del posterior desarrollo filosófico y jurídico de la dignidad.

Ahora bien, ése es el punto de partida. A lo largo de los siglos posteriores ha habido un desarrollo de la noción de dignidad humana, sobre todo dentro del humanismo ${ }^{16}$. Se trata de una fuerza histórica, que vincula ese desarrollo con el cristianismo, que ha generado un proceso de secularización en el que el concepto de libertad y dignidad —más allá de sus fundamentos teológicos- llega a explicarse filosóficamente con argumentos racionales que están al alcance de cualquier inteligencia, como la importante y conocida convicción de Kant al mantener que la persona ha de ser tratada siempre como fin y nunca como medio. Dicho con otras palabras,

15 K. Jaspers, Die geistige Situation unserer Zeit, 5. ${ }^{\text {a }}$ ed., Berlin, 1932, p. 135: «El hombre es más de lo que de él se sabe».

${ }^{16}$ Cfr. G. Pico della Mirandola, Oratio de hominis dignitate, Bologna, 1496 (ed. de Wimpfeling, Opera Omnia, Straßburg, Prüs, 1504). 
la conciencia y la explicación de la dignidad humana que tiene origen en el cristianismo se hace patrimonio del pensamiento humano.

También de la tradición cristiana se derivan otras consecuencias que no han de perderse de vista, sigue explicando Starck. Entre ellas, que apoyándose en la dignidad es como se han descrito los límites entre lo humano respecto de lo no humano y lo inhumano. $\mathrm{Y}$ otra no menos importante, que la dignidad corresponde a cada ser humano concreto. Convicción que ha seguido manteniendo el humanismo europeo al rechazar toda idea de que se vea reducido a un simple medio para alcanzar fines sociales, colectivamente organizados de forma tecnocrática. Pues, que un ser humano se considere como simple pieza de engranaje, como mero cuadro útil para el desarrollo social, es denigrarlo y privarlo de su dignidad.

Por tanto, una fundamentación de la dignidad, también para que dicha noción no pierda su sentido originario, ha de apoyarse en su iter histórico, a saber: su anclaje nuclear en el mensaje cristiano, su posterior formulación filosófica y, por último, la exigencia de garantía jurídica.

En definitiva, la realista recuperación que propone Starck del patrimonio histórico espiritual supone advertir que la imagen bíblica del hombre es la convicción y la base imprescindible para el desarrollo de las garantías jurídicas de la dignidad. Y, a su vez, para detectar las ideologías que intentan destruirla, como puede ser el conductismo psicológico de Skinner o el existencialismo sartreano, a los que hace especial referencia al reconocer que el behaviorismo intenta presentarse como ciencia filosófica empírica y lo que en realidad hace es facilitar un fundamento para el menosprecio humano, o el riesgo de los planteamientos meramente culturalistas como el de Sartre, para quien la tesis de Skinner sería igual de legítima que el egoísmo radical ${ }^{17}$.

Sobre la base nuclear que da lugar a la alta estima que la persona tiene en la cultura europea, actualmente se reclama una fundamentación más rigurosa, profunda y universal que la hecha hasta ahora por el humanismo, que la fundó en la ley natural. Para proseguir en dicha fundamentación se han de tener en cuenta los diversos hallazgos y desarrollos que la inteligencia humana ha ido haciendo a lo largo de los siglos posteriores. Entre ellos está el que la modernidad haya planteado con radicalidad la diferencia entre la naturaleza y la libertad, entre lo natural y lo racional ${ }^{18}$. Los

17 Cfr. Ch. STARCK, «La dignidad del hombre como garantía constitucional, en especial en el Derecho alemán», op. cit., p. 247, en la que hace referencia a la obra de B. F. SKINNER, Más allá de la libertad y de la dignidad, Barcelona, Fontanella, 1973.

18 Otro modo de plantear la misma cuestión en R. SPAEMANN, Lo natural y lo racional, Madrid, Rialp, 1989. 
modernos, recogiendo el legado de las vivencias de los siglos precedentes, plantearon que la libertad es algo más profundo que el libre arbitrio como característica de algunos actos humanos ${ }^{19}$. Intuición, por otra parte, asequible a la experiencia humana elemental, pues toda persona puede reconocer que cuando hace las cosas libremente, «porque le da la gana», aun sin razones aparentes que lo apoyen, sabe que su querer es anterior a su actuación, y que ese querer libre es lo que posteriormente hará voluntario su acto. $\mathrm{Y}$ aunque los filósofos modernos no han conseguido un desarrollo adecuado sobre la libertad - y a pesar de que no faltan los naturalismos y biologismos extremos-, no cabe duda de que han contribuido a arraigar la convicción de que lo que separa al ser humano del resto de la naturaleza es una diferencia más radical y profunda de la que se ha desarrollado en la tradición clásica.

Los intentos de seguir considerando la naturaleza y la ley natural como enclave último de la dignidad ${ }^{20}$ no sólo presentan grandes dificultades de supervivencia en el clima espiritual de nuestro tiempo, sino que encierran en el fondo un patente carácter problemático. Palacios ha analizado algunos de ellos ${ }^{21}$, entre los que el más profundo desde el punto de vista antropológico es descrito con las siguientes palabras: «Uno de los problemas más evidentes que ha planteado siempre (el fundamentar la dignidad en la naturaleza) es el cómo avenir el concepto que supone la naturaleza humana con la afirmación de la libertad del hombre. En efecto, si la naturaleza es fin, como escribe Aristóteles al principio de su Política (I, 2, 1252 b32), ¿Cómo puede el hombre tener impuesta su naturaleza y tener al mismo tiempo la capacidad de imponerse a sí mismo sus propios fines? ¿Cómo se puede ser por naturaleza algo y ser a la vez libre para llegar a serlo? ¿Cómo cabe concebir - para decirlo con expresión de Millán-Puelles- la síntesis humana de naturaleza y libertad?» ${ }^{22}$.

Por otra parte, la naturaleza, a pesar de haberse considerado inicialmente como principio de operaciones de los seres vivos, terminó considerándose de un modo inmovilista, lo que aparece contrapuesto con la enorme capacidad humana de innovación y creatividad, y con la imprevisibilidad de la historia. El pensamiento moderno y contemporáneo asume la

${ }^{19}$ Esta intuición arranca de más lejos. Cfr. J. DE GARAY, El nacimiento de la libertad. Precedentes de la libertad moderna, Sevilla, Thémata, 2006.

20 J. Maritain, El hombre y el Estado, 2." ed., Madrid, Encuentro, 2002, pp. 87, 90-91 y $92-95$.

${ }^{21}$ Cfr. J. M. Palacios, La condición de lo humano, op. cit., pp. 49-61.

22 Ibid., pp. 49-50. 
importancia del tiempo y de la cultura para la antropología (bastaría citar a Dilthey, Bergson o Heidegger). Tras el nacimiento de la antropología cultural como ciencia desgajada del resto se ha asistido durante decenios al debate entre naturaleza y cultura. No han faltado quienes defendieran la primera, pero en clara desventaja con respecto a los culturalistas, que han llegado a negar incluso que el ser humano tenga naturaleza. Lo cierto es que en este interminable debate — afectado a radice por un dualismo- se ha considerado tanto la naturaleza como la cultura como si fueran dos realidades ya previamente constituidas, pugnando entre sí o negándose una a la otra. Y esa prolongada disputa, en caso de haberse cerrado, lo ha hecho en falso, pues no se ha llegado a concluir qué es lo permanente y hasta qué punto es moldeable lo innato del ser humano.

Tras la esterilidad de ese debate — cultura versus naturaleza-, y frente a los prejuicios a hablar de ley natural de la modernidad y a la decisión de la posmodernidad de eliminar esa noción del lenguaje filosófico y jurídico, lo que parece claro es que lo dicho en la tradición al respecto no lo explica todo. Desde lo natural es difícil explicar la libertad y su capacidad de dominio sobre lo natural que el hombre alcanza con la ciencia y la tecnología. Además, la tradición metafísica plantea la dificultad de desarrollar la antropología con un lenguaje filosófico proveniente del conocimiento del cosmos, convirtiéndola en una filosofía segunda dependiente de aqué1la. Y en cierto modo el drama antropológico de la modernidad consiste en que, a pesar de abrir temas nuevos aportados por las raíces culturales de las que procede - la libertad, la intimidad de la subjetividad, su capacidad de proyecto y creatividad, etc.- - intenta desarrollarlos con la misma filosofía que explica el cosmos. Como señala Polo, a diferencia del avance exponencial de la ciencia, en filosofía, desde hace siglos, no se han aportado nuevas ideas. Los diversos autores siguen barajado de modos diversos los mismos elementos y se aborda el estudio del cosmos y del hombre desde una perspectiva simétrica ${ }^{23}$.

A lo largo del siglo xx se advierte cada vez con más claridad la necesidad de un nuevo andamiaje conceptual para hablar del ser humano. Entre otras cuestiones se intuye que para el ser humano las relaciones son algo fundamental, mucho más que accidentes metafísicos: se las denomina

${ }^{23}$ Para la tesis de la filosofía moderna como simetrización de la metafísica clásica cfr., entre otros lugares, L. PoLO, Antropología trascendental, vol. I, Pamplona, Eunsa, 1999, p. 90, e ÍD., «La coexistencia del hombre», en R. AlviRA (ed.), El hombre: inmanencia y trascendencia, vol. I, Pamplona, Universidad de Navarra, 1991, pp. 33-48. 
relaciones ontológicas, aunque está aún sin precisar su enclave ${ }^{24}$. En palabras del López Quintás: «Los esquemas "causa-efecto", "acción-pasión”, son monodireccionales, deterministas (un golpe dado sobre la mesa causa ineludiblemente un efecto determinado: cierto sonido). En cambio, el esquema "apelación-respuesta" es circular, promocionador de la libertad (un hombre que hace a otro una sugerencia lo apela a tomar opción y dar respuesta)» ${ }^{25}$. Es decir, se está pidiendo una ampliación de la ontología que distinga entre las cosas y las personas, entre el ser del cosmos y el ser de cada hombre, y se desarrolle una ontología especial para la antropología y la libertad.

\section{REFLEXIÓN EN TORNO A LA DIGNIDAD HUMANA}

Volviendo de nuevo a la dignidad personal, comencemos repasando los mensajes que trasmite la experiencia humana elemental que, como ya vimos, despertó a mediados del siglo Xx con carácter generalizado una serie de profundas convicciones.

En primer lugar, se redescubre que la realidad auténtica debe buscarse en los seres singulares. Este nuevo punto de partida ayuda a afrontar la cuestión antropológica, cuya realidad central es la persona que siempre es concreta, real, irrepetible y sobre la que poco sirven generalidades y abstracciones. En palabras de López Quintás: «La fidelidad a lo singular irrepetible inspira en buena medida el movimiento de "retorno a lo concreto" iniciado por Husserl en 1900 y proseguido por el movimiento existencial y el personalista a partir del trauma que supuso la primera contienda mundial. La experiencia de la vida en guerra reveló a tres autores de tradición hebrea, F. Rosenzweig, Gabriel Marcel y Martin Buber, que la realidad auténtica debe ser buscada en los seres concretos y de modo singular en las entidades relacionales que surgen en los fenómenos de encuentro. Para dar alcance a tales entidades deben sustituirse los esquemas "sujeto-objeto" y "yo-ello" por el esquema "yo-tú" " ${ }^{26}$.

${ }^{24}$ Cfr. X. ZubirI, «Respectividad de lo real», Realitas, núm. III-IV (1976-1979), pp. 14-43, donde, antes de exponer su noción de respectividad, hace un recorrido por los diversos sentidos que la relación ha tenido a lo largo de la historia de la filosofía, distinguiendo entre relación categorial, ontológica y transcendental.

${ }^{25}$ Cfr. A. López Quintás, «La antropología dialógica de F. Ebner», en J. DE SAHAGúN LuCAS, Antropologías del siglo Xx, Salamanca, Sígueme, 1979, p. 152.

${ }^{26}$ Ibid., p. 154. 
Ahora bien, ¿de qué habla esa experiencia humana que despunta una y otra vez como florece la primavera en terrenos abandonados y llenos de residuos? La experiencia viene a decir que cada persona es algo nuevo y que con cada nacimiento es como si todo volviera a empezar. Recordemos el significado decisivo del nacimiento que sugiere Hölderlin en su poesía El Rhin: «Lo mejor lo puede el nacimiento y el rayo de luz que encuentra al recién nacido», o las geniales páginas de Hannah Arendt para quien en cada nacimiento algo singularmente nuevo aparece en el mundo.

La experiencia también advierte que las relaciones, sobre todo la relación varón-mujer y persona-comunidad, son imprescindibles para el crecimiento del sujeto, para el emerger de su autoconciencia y el ejercicio de su autodeterminación. De ahí que el yo —y más radicalmente la persona desde la que emerge el yo consciente- se presente a sí mismo como relacional y buscador de sentido, abierto al don y capaz de donación, y se concluya que la libertad es nada si no sirve con responsabilidad a la verdad del amor.

Cada persona tiene valor por sí misma, de lo que se deriva que nadie tiene derecho sobre otra persona. Por eso se advierte que la dignidad, aunque ha de ser respetada por uno mismo y por los demás, sin embargo, no es otorgada ni por uno ni por los otros hombres. La dignidad de cada cual es recibida junto con el ser y la vida, por lo que no depende de los ojos de otro hombre, ni de lo que otros coetáneos le puedan dar. De ahí que Hannah Arendt pueda afirmar que cada ser humano es algo nuevo: «Lo nuevo siempre aparece en forma de milagro. El hecho de que el hombre sea capaz de acción significa que cabe esperar de él lo inesperado, que es capaz de realizar lo que es infinitamente improbable. Esto es posible debido sólo a que cada hombre es único, de tal manera que con cada nacimiento algo singularmente nuevo entra en el mundo. Con respecto a ese alguien que es único cabe decir verdaderamente que nadie estuvo allí antes que él» ${ }^{27}$, de modo que el poder de una sola libertad puede hacer cambiar el rumbo de la historia.

La dignidad no está en función de la utilidad de la acción de alguien, de su fuerza, belleza, inteligencia, riqueza o salud. La dignidad se tiene sólo por existir y habla del inmenso valor del hombre y de cada hombre, por muy pobre, débil o sufriente que sea, lo que implica el acogimiento de toda vida humana, desde el momento en que se anuncia hasta el momento en que se apaga ${ }^{28}$.

\footnotetext{
${ }^{27}$ H. Arendt, The Human Condition, Chicago, University of Chicago Press, 1974 (trad. cast., La condición bumana, Barcelona, Paidós, 1993, p. 202).

${ }^{28}$ Cfr. J. Ratzinger, El elogio de la conciencia, Madrid, Palabra, 2010, p. 48.
} 
Sobre esta experiencia reflexionan una serie de pensadores europeos procedentes de variadas corrientes filosóficas — la fenomenología, el existencialismo, la escolástica, el neotomismo, la hermenéutica, el personalismo, la antropología dialógica, etc.- - que comparten el inconformismo con las corrientes de pensamiento generalizadas en Europa: positivismo, cientificismo, capitalismo, marxismo, nihilismo y los totalitarismos de corte hegeliano, así como el retroceso de la cultura cristiana que reconocen como el cimiento del humanismo europeo.

Todos ellos son conscientes de la necesidad de una alternativa teórica que dé razón de las experiencias vitales y de la verdad de cada ser humano concreto - con cuerpo y sentimientos-y de su entorno relacional cercano, de su preocupación por la búsqueda de sentido — a su vida, trabajo y descanso- y la mejora de la sociedad. Se reconoce que la teoría - desprestigiada tras décadas de pragmatismo-, aunque no sea suficiente para salir de las crisis, resulta imprescindible para este propósito. «La raíz de lo que deberíamos llamar theoría —afirma Gadamer- es ver lo que es» en lugar de lo que cada uno desearía que fuese. De este modo la theoría - que en él adquiere cierto sentido sapiencial — funda la praxis y a la vez la rebasa, «al hacer posible una vida a la que se puede decir "sí" $"$ ".

\section{LA DIGNIDAD COMO VALOR UNIVERSAL: SIGNIFICADO Y ALCANCE}

Por otra parte, la dignidad tiene que ver con cada ser humano concreto y con esa profunda característica suya que es la libertad. Quizá por eso la gran mayoría de los humanistas del siglo xx, en lugar de hablar del hombre en abstracto, han retomado la antigua noción de persona, para retornar, frente a la barbarie de las guerras mundiales, a la dignidad de cada hombre por el hecho de serlo. Su objetivo se mueve en la línea de reconstruir el humanismo, renovándolo en torno a la persona singular, de ahí el apelativo en torno al que algunos los vienen agrupando: el perso-

${ }^{29}$ Cfr. H-G. Gadamer, Lob der Theorie, Frankfurt am Main, Suhrkamp, 1983 (trad. cast., Elogio de la teoría, Barcelona, RDA Libros, 2013, pp. 50-51), donde va exponiendo con brillantez que la Theoria como sabiduría, que en su sentido originario significa contemplar, no es una acumulación de información ni un acto momentáneo, sino como una actitud, un lugar o un estado en el que se permanece y significa «el "estar ahí" en el bello doble sentido que no sólo significa presencia, sino también que el presente está "por entero ahî”». 
nalismo. En este sentido se habla de que, tras el giro antropológico de la filosofía moderna, se ha producido el giro personalista de la antropología o el paso del humanismo al personalismo ${ }^{30}$. Dicho con otras palabras, desde esta nueva perspectiva el fundamento último de la dignidad humana, ese algo previo a la acción y garante de su inviolabilidad, vendría a ser algo más profundo e interior que su naturaleza específica, que no se niega, es decir, la persona.

Toda esta corriente busca distinguir entre naturaleza y persona, y así como el humanismo europeo se centró en la naturaleza y en la ley natural, un personalismo con calado ontológico permitiría, más allá de la naturaleza, llegar a un nivel antropológico más radical: el de ser personal.

Sin embargo, para el pensamiento clásico de corte abstracto, convencido en parte de que la inteligencia humana sólo conoce lo general y abstracto, porque lo individual y concreto pertenece únicamente al conocimiento sensible, ve con reparos un pensamiento personalista, en el sentido de considerar como imposible el fundamentar algo universal en la persona, porque cada una de éstas son individuales y concretas. Son aquellos que siguen pensando que sólo la naturaleza, en cuanto que es común a todos, puede fundar la universalidad.

La dignidad humana, que cada persona tiene precisamente por ser única e irrepetible, es una dignidad intransferible. No obstante, al gozar de ella cada ser humano se puede decir también que es universal. Sin embargo, parece tratarse de otro modo de universalidad, universalidad a otro nivel ontológico que, sin anular nada de lo dicho anteriormente, alcanza un nivel más profundo y permitiría un fundamento más sólido para la moral, pues, en definitiva, ésta no sería tal si no acogiera la libertad para $\operatorname{amar}^{31}$.

Un aspecto de la universalidad de la dignidad es que no depende de condicionamientos o diferencias raciales o por razón de sexo. En el siglo xx - a pesar de lo mucho que resta por hacer- se han alcanzado algunas cotas en torno a la igualdad de oportunidades, a la igualdad de derechos inherentes al hecho mismo de ser persona. Así, por primera vez en la historia se ha concedido el derecho a voto, por ejemplo, a las mujeres y a las personas de color. Respecto a la dignidad de la mujer, aunque en las culturas avanzadas no ofrece discusión, se trata de una cuestión sobre la que siguen

30 Cfr. A. Domingo Moratalla, Un humanismo del siglo xx: el personalismo, Madrid, Cincel, 1985.

${ }^{31}$ Cfr. Á. QuiRós et al. (coords.), El primado de la persona en la moral contemporánea, Pamplona, Servicio de Publicaciones de la Universidad de Navarra, 1997. 
pesando los prejuicios y tanto antropológica como teológicamente la cuestión no se ha abordado aún con la necesaria profundidad ${ }^{32}$.

Habría que concluir destacando los dos sentidos que de la dignidad ofrece Millán Puelles: la ontológica y la adquirida ${ }^{33}$. En el primer sentido se trata de una dignidad radical e innata - a la que aquí nos hemos referido hasta ahora-, y el segundo sentido es un plus de dignidad que cada cual puede adquirir con su modo de vivir. En efecto, la conciencia de la dignidad propia y ajena y el ser coherente con ella hace que algunas personas tengan una autoritas personal, una respetabilidad y una influencia que emanando de su honradez se impone sin violencia.

Finalmente, también se podría hablar de la dignidad en un tercer sentido: el de la conciencia que la humanidad va teniendo sobre ella y su influjo en las costumbres y las leyes. En este sentido, la dignidad humana es sobre todo lucha por la dignidad, porque tiene de hecho progresos y retrocesos. Pero si se repasa la historia desde sus orígenes se puede advertir un avance cultural que tímidamente progresa. Ahora tenemos, al menos vaga, una mayor conciencia de la dignidad que la mayor parte de las culturas anteriores. Conseguirla ha costado muchos esfuerzos, titubeos, fracasos, heroísmos, horrores. Se trata de un gran relato, de la genealogía de la grandeza común de la humanidad, donde los seres humanos encuentran su verdadera identidad más allá de las anécdotas nacionales. Una historia grande y una historia agradecida, porque recuerda los heroísmos que han hecho posible ahorrarnos de tantos dolores ${ }^{34}$. Historia que, al final, se convierte en fundamento vivo aunque precario de la ética. En efecto, este saber sapiencial no se consigue de una vez por todas. En las épocas de bonanza se tiene el peligro de la modorra de la comodidad y de la queja, olvidando la génesis de lo que disfrutamos y su precariedad. Por el contrario, las épocas de crisis pueden ser ocasión de profundizar en lo realmente válido, de dar como una vuelta de tuerca para afianzarse en lo realmente valioso. Las nuevas circunstancias siempre recuerdan que los caminos no están hechos y que los seres humanos carecemos de manual de instrucciones precisas. No carecemos totalmente de pautas, pues en el fondo de nuestro ser poseemos una brújula que orienta los pasos. La nostalgia por la dignidad

32 Por primera vez en la historia un documento del Magisterio de la Iglesia lleva por título La dignidad de la mujer (Juan Pablo II, Carta Apostólica Mulieris Dignitatem, 1988). Presentado como una meditación, constituye una invitación a proseguir en dicha investigación.

33 Cfr. A. Millán Puelles, Sobre el hombre y la sociedad, Madrid, Rialp, 1979.

34 Como método de enseñanza hay intentos de recoger estos hitos. Cfr. J. A. Marina y M. DE LA VÁlgonma, La lucha por la dignidad, Barcelona, Anagrama, 2000. 
perdida ha servido en el siglo xx para dar un paso más hacia ella y — gracias al sendero recorrido hasta ahora- existen junto a muchos planos falsos otros cada vez mejor trazados para conseguir la dignidad. Acicate para proseguir en la brecha de una de las mejores conquistas de la humanidad, pues, al igual que los canteros de Rilke se transformaban en la piedra que tallaban, el ser humano halla su dignidad al construirla.

Acuciante fue la Declaración Universal de Derechos de 1948 y, tras su estela, un año más tarde, la influyente y vigente hasta hoy Ley Fundamental alemana (Grundgesetz), aprobada en Bonn. El preámbulo y el art. 1.1 de ese texto — así como su blindaje en el art. 79.3- evidencian de forma definitiva el respeto a la dignidad que da paso a un tiempo nuevo:

«Consciente de su responsabilidad ante Dios y ante los hombres, animado de la voluntad de servir a la paz del mundo, como miembro con igualdad de derechos de una Europa unida, el pueblo alemán... [preámbulo] se da una Ley Fundamental que expresamente consagra que "la dignidad humana es intangible" (unantastbar) y como tal "respetarla y protegerla es obligación de todo poder público" (art. 1.1). Es, pues, "derecho directamente aplicable y, además, principio normativizado y derecho vinculante, incluso para el poder constituyente, que queda sustraído a cualquier futura reforma o modificación constitucional posterior" (art. 79.3)».

Advirtamos que el reconocimiento y garantía de la dignidad humana en la Ley Fundamental alemana implica no sólo la obligación estatal de respetar la dignidad, sino que exige también normativizar esta garantía sobre la base de su intangibilidad general, que tiene validez con independencia de la existencia de una posición jurídica subjetiva ${ }^{35}$.

Tras la Declaración Universal de los Derechos Humanos ${ }^{36}$ y la Ley Fundamental alemana (1949) ${ }^{37}$, a partir de 1975 la protección a la dignidad pasa a fundamentar muchas de las nuevas Constituciones europeas: las de Suecia, Grecia, Portugal, España, Suiza, Finlandia, la Carta de Dere-

35 Así se pronuncian constitucionalistas como E. BENDA, R. Dreier, P. Häbert o Ch. Starck. Cfr. el ya citado artículo de este último «Introducción a la dignidad humana en el Derecho alemán», Anuario Iberoamericano de Justicia Constitucional, núm. 9 (2005), pp. 489-697.

36 Con anterioridad había sido reconocida en la Constitución irlandesa de 1937 y en la italiana de 1947.

37 También antes de la Ley Fundamental alemana (1949), las Constituciones de los Länder de Babiera, Hesse, Renania Palatinado y el Sarre, como reacción directa al desprecio del hombre nacionalsocialista, contenían la garantía de la dignidad, considerándolo como derecho fundamental y derecho humano elemental. Cfr. Ch. STARCK, ibid. 
chos Fundamentales europea (2000) y las de otros Estados centroeuropeos que a partir de 2004 han ingresado en la Unión Europea: Letonia, Lituania, Polonia, Eslovaquia y República Checa.

Tras haber puesto de manifiesto no sólo la conveniencia, sino la necesidad y las dificultades que entraña fundamentar más sólida y universalmente la dignidad, sería preciso indagar en aquellas reflexiones que puedan hacerlo posible, aunque esta cuestión excede al espacio y a las posibilidades del presente trabajo. 